\title{
IN SITU MEASUREMENTS OF THE ACTIVATION ENERGY FOR D.C. CONDUCTION IN POLAR ICE
}

\author{
By Charles R. Bentley \\ (Geophysical and Polar Research Center, University of Wisconsin, Madison, Wisconsin 537o6, \\ U.S.A.)
}

Abstract. During the $1976-77$ Antarctic field season, electrical resistivity profiling was carried out in the south-eastern quadrant of the Ross Ice Shelf. Drilling to a depth slightly greater than $300 \mathrm{~m}$ at the same site, where the total ice thickness is $425 \mathrm{~m}$, permitted temperature determinations (personal communication from B. L. Hanson and J. H. Rand) that can be extrapolated to the ice-water boundary. Numerical modelling of the apparent resistivity, allowing for a continuous variation of temperature and density, and hence conductivity, with depth, was done in the same manner as has been described previously (Bentley, I977). Temperatures calculated by assuming no basal melting or freezing show excellent agreement with those measured. Two models of apparent resistivity, taking the activation energy in the solid ice to be $0.15 \mathrm{eV}$ and $0.25 \mathrm{eV}$, respectively, bracket the observed data, with the points tending to favor the lower value. This is in satisfactory agreement with (although perhaps slightly lower than) other measurements on polar ice. Assuming that the same temperature model applies at the site of the earlier measurements (Bentley, I977), only $30 \mathrm{~km}$ away and approximately "up-stream", leads to apparent resistivity models, with activation energies of $0.15 \mathrm{eV}$ and $0.25 \mathrm{eV}$, that again bracket the observations. The effect of other possible causes for the change of conductivity with depth besides temperature, such as varying grain size, crystal orientation, $\mathrm{CO}_{2}$ content, etc., is unknown but believed to be small because of the similar history of all the ice in the relevant depth range, about $100-35^{\circ} \mathrm{m}$, over which the conductivity increases by a factor of 2 . The conductivity in the ice at $100 \mathrm{~m}$ depth (temperature $-23^{\circ} \mathrm{C}$ ) at both sites is within $\pm 10 \%$ of $1.4 \times 10^{-5} \Omega^{-1} \mathrm{~m}^{-1}$. We conclude that an activation energy of $0.20 \pm 0.05 \mathrm{eV}$ not only can be used for modelling, but also closely represents the true value for ice-shelf ice.

\section{DISCUSSION}

J. KLINGER: What kind of electrode did you use and what was the time between applying the current and the measurement of the potential difference?

C. R. Bentley: For most separations the potential electrodes were sections of copper tubing about $20 \mathrm{~mm}$ in diameter and $0.2 \mathrm{~m}$ long. At the shortest spacings, large nails were used. The current electrodes were solid copper rods about $\mathrm{I} \mathrm{m}$ long and $\mathrm{I} 5 \mathrm{~mm}$ in diameter, driven their full length (except at short separations) into the firn. The contact resistance at the current electrodes was reduced by dousing with salt water. Currents and voltages were read as soon as their rate of drop decreased enough to permit accurate simultaneous readings of the ammeter and the electrometer. Readings were continued until the rate of drop became very slow. (For further discussion of techniques, see Bentley (r977).)

G. DE Q. Robin: Could you detect saline ice at the bottom of the ice shelf?

Bentley: A layer of saline ice at the bottom of the shelf would be difficult to detect, because (a) the extremely high conductivity in the underlying sea-water makes the method basically insensitive to a conductive basal ice layer, and (b) the modification of apparent resistivities would be seen only at large separations where the signal-to-noise ratio is low. I would estimate 
(lacking as yet any quantitative modelling) that such a layer would have to have a thickness at least $10 \%$ that of the shelf to be detected. Sensitivity to a basal resistive layer, such as has now been observed at several locations on the ice shelf, is much greater.

W. F. Budd: The temperature profile seems to show no growth of ice from ocean water on the bottom. Is that what you conclude from the profile and the d.c. conductivity?

Bentley: Yes. I believe that the balance at the ice-water interface is within $\pm 0 . \mathrm{m}_{\mathrm{mear}}^{-1}$ of zero.

\section{REFERENGE}

Bentley, C. R. 1977. Electrical resistivity measurements on the Ross Ice Shelf. Fournal of Glaciology, Vol. I8, No. 78 , p. $15^{-35}$.

\section{THE DISLOCATION FORMATION VOLUME IN ICE}

\section{By R. M. J. Cotterill and O. Bøgker Pedersen}

(Department of Structural Properties of Materials, the Technical University of Denmark, Building 307, DK-280o Lyngby, Denmark, and Metallurgy Department, Danish Atomic Energy Commission Research Establishment Risø, DK-40oo Roskilde, Denmark)

Abstract. Relaxations around a shear dislocation loop on a basal plane in ice have been studied by molecular dynamics. The model intermolecular potential included directional components which stabilized the open ice structure. A random phase approximation was introduced to simulate the disordered arrangement of hydrogen bonds. The dislocation formation volume was found to be zero within the limits of computational error. This paper is published in full in Nuclear Metallurgy, Vol. 20, Pt. I, I976, p. 572-81.

\section{DISGUSSION}

J. W. GLEN : Your "dislocation loop" consists of a movement of only two molecules by $\frac{1}{2} b$ each in opposite directions. This is a very minimal dislocation - it is hardly a line defect and has no perfect crystal in the middle of the loop. Is it sufficiently like these larger dislocations for it to be safe to assume that volume changes are comparable? Is there any reason why your model, with cyclic boundary conditions, could not be used for a straight dislocation right across the cell?

O. B. Pedersen: I think our model could also be used for a straight dislocation. However, we have a special interest in this particular dislocation configuration, which could be called a "point dislocation" rather than a "dislocation loop". In molecular dynamics studies of crystals of the noble gases Cotterill and others (1974) observed that point dislocations were spontaneously generated at the onset of melting. We would like to know whether this is a general phenomenon and have therefore studied the point dislocation and not the line dislocation. It is certainly dangerous to make direct comparisons between the formation volume of a point dislocation and that of a line dislocation.

\section{REFERENCE}

Cotterill, R. M. J., and others. 1974. Molecular dynamics studies of melting. III. Spontaneous dislocation generation and the dynamics of melting, by R. M. J. Cotterill, W. D. Kristensen and E. J. Jensen. Philosophical Magazine, Eighth Ser., Vol. 30, No. 2, p. 245-63. 